\title{
Planejamento estratégico federal brasileiro de hidrelétricas e os indicadores de desempenho socioambientais
}

\author{
Brazilian federal strategic planning for hydroelectric and \\ socio-environmental key performance indicators
}

Felipe Affonso Dantas dos Santos ${ }^{1}$ (iD), Laura de Britto Pereira Viana ${ }^{1}$ (D), Cristina Aparecida Gomes Nassar ${ }^{1}$ (D)

1'Universidade Federal do Rio de Janeiro - UFRJ, Rio de Janeiro, RJ, Brasil. E-mails: felipeaffonso@poli.ufrj.br, laurabpviana@gmail.com, cagnassar@hotmail.com

\begin{abstract}
Como citar: Santos, F. A. D., Viana, L. B. P., \& Nassar, C. A. G. Planejamento estratégico federal brasileiro de hidrelétricas e os indicadores de desempenho socioambientais. Revista de Gestão de Água da América Latina, 17, e23. https://doi.org/10.21168/rega.v17e23
\end{abstract}

\begin{abstract}
RESUMO: O presente artigo identificou e avaliou a utilização de indicadores de desempenho socioambientais no âmbito do planejamento estratégico federal, através da avaliação do planejamento estratégico da matriz energética brasileira, para os projetos de empreendimentos hidrelétricos. Identificou ainda a utilização destes indicadores nas demais fases do empreendimento. Foi observado que os estudos do Plano Decenal de Expansão de Energia - PDEs foram elaborados com base em metodologias específicas que utilizaram indicadores de avaliação socioambiental, definidos por Notas Técnicas. As avaliações foram desenvolvidas como critério de seleção dos empreendimentos para composição do PDE, no entanto, apresentaram informações dos indicadores pelo conjunto de Usina Hidrelétricas UHEs previsto, ao invés de apresentá-los individualmente, permitindo que UHEs de baixo desempenho socioambiental sejam compensadas por UHEs mais eficientes. Grande parte dos indicadores abordados foram absolutos, não levando em consideração a potência gerada versus o impacto socioambiental. Os indicadores utilizados para obtenção de avaliação socioambiental, no planejamento estratégico, não foram necessariamente os mesmos utilizados durantes as fases subsequentes do projeto. Tal fato, resultou em uma incoerência dos dados, pois ao se divulgar apenas os dados compilados do conjunto de UHEs, não se tem uma visão detalhada dos indicadores de cada empreendimento e seus respectivos desempenhos. 0 artigo destaca a importância da integração dos indicadores socioambientais nos momentos de planejamento estratégico com os indicadores do licenciamento ambiental, para a avaliação do desempenho ao longo do tempo dos empreendimentos hidrelétricos. Embora tenham sido utilizados indicadores socioambientais, há uma subutilização desses indicadores, no que tange à comunicação do desempenho dos empreendimentos. A subutilização se estende para a tomada de decisão de alocação de recursos e soluções de problema de natureza socioambientais no planejamento estratégico federal brasileiro de empreendimentos hidrelétricos.
\end{abstract}

Palavras-chave: Indicador Socioambiental; Hidrelétricas; Indicadores de Desempenho; Planejamento Estratégico; Licenciamento Ambiental.

ABSTRACT: This article identified and evaluated the use of socio-environmental key performance indicators during the federal strategic planning of hydroelectric plants, through the assessment of the strategic planning of the Brazilian Energy Matrix. It has also identified the use of these indicators during the subsequent stages of the projects. It is observed that the studies of the Ten-Year Energy Expansion Plan - PDE were developed based on specific methodologies that used socio-environmental assessment indicators, defined by Technical Notes. The evaluations were developed as a criterion for projects selection when defining the PDE composition, however, present information from the indicators by the set of expected UHEs, instead of presenting them individually, allowing UHEs of low socioenvironmental performance to be compensated by more efficient UHEs. Large part of the indicators addressed are absolute, not taking into account the power generated versus the socio-environmental impact. The indicators used to obtain socio-environmental assessment, in strategic planning, are not necessarily the same used during the subsequent phases of the project. This fact resulted in a data inconsistency, as by disclosing only the consolidated information from the whole group of hydroelectric plants, it is not possible to have a detailed view from the indicators

Recebido: Setembro 16, 2020. Revisado: Novembro 19, 2020. Aceito: Dezembro 04, 2020. 
of each project, as well as its performance. The article highlights the importance of an integration of socioenvironmental indicators during the strategic planning stages along with the environmental licensing phase, for the performance assessment of hydroelectric projects over time. Although socio-environmental indicators are used, there is an underutilization of it with regard to the communication of the performance of the enterprises, as well as for the decision-making process of resources allocation and solutions of problems related to socio-environmental origin, in Brazilian federal strategic planning of hydroelectric projects.

Keywords: Socio-environmental Key Indicator; Hydroelectric; Key Performance Indicators; Strategic Planning; Environmental Licensing.

\section{INTRODUÇÃO}

Os empreendimentos hidrelétricos possuem alta representatividade na matriz energética brasileira, sendo responsáveis atualmente por $60 \%$ da geração da energia elétrica. As 217 usinas hidrelétricas em operação totalizam $102 \mathrm{GW}$ de potência instalada, e, a maioria situa-se nas bacias do Paraná e Atlântico Sudeste, no Sudeste e Sul do Brasil (Brasil, 2019a).

O Conselho Nacional de Política Energética (CNPE) é o órgão de assessoramento do Presidente da República para formulação de políticas e diretrizes de energia e, conforme estabelecido na Lei 9.478/97, uma de suas atribuições é rever periodicamente a matriz energética nacional, instrumento que projeta e avalia diferentes cenários de mercado e seus efeitos. Atualmente, a formulação destas políticas e diretrizes vem sendo realizada sob a coordenação do Ministério de Minas e Energia (Brasil, 2007b).

Com o intuito de amparar tecnicamente a missão do Ministério de Minas e Energia (MME), em 2004, foi editada através da Lei 10.847/2004, a criação da Empresa de Pesquisa Energética (EPE). A EPE é vinculada ao Ministério das Minas e Energia, e, tem como finalidade, disponibilizar estudos que auxiliem a definição dos planos, programas e diretrizes para o planejamento energético de longo prazo do governo brasileiro. Em outras palavras, as pesquisas elaboradas pelo EPE visam contribuir para o cumprimento dos princípios e objetivos da Política Energética Nacional (Brasil, 2007b).

0 conjunto de estudos sobre a expansão da oferta e da demanda de energia nacional, nos próximos 25 anos, é consolidado em um relatório denominado Plano Nacional de Energia (PNE). 0 relatório do Plano Decenal de Expansão de Energia (PDE), por sua vez, detalha as metas e define os projetos a serem executados nos dez anos seguintes (Brasil, 2007b). Dessa forma, o PNE define as estratégias e antecipa a direção do setor no longo prazo, enquanto o PDE aponta de maneira mais detalhada quais serão as ações e metas no médio prazo (Brasil, 2011a).

No planejamento estratégico de longo prazo, o principal instrumento de avaliação de desempenho socioambiental dos empreendimentos hidrelétricos são os estudos do Plano Decenal de Expansão da Energia - PDE, elaborado anualmente pela EPE, e suas metodologias de avaliação socioambiental. O PDE contempla tanto uma avaliação socioambiental integrada, que leva em consideração os impactos de diferentes fontes de geração de energia, como uma avaliação socioambiental específica para hidrelétricas (Brasil, 2018c; Tolmasquim, 2012). Adicionalmente, no documento são projetadas as futuras contribuições provenientes de cada fonte energética e seus potenciais de geração de energia elétrica, bem como a previsão de implantações de novos empreendimentos de diferentes fontes, consideradas fundamentais para a expansão no ciclo dos dez anos seguintes.

Em paralelo, o ciclo de avaliação da viabilidade e planejamento para instalação de empreendimentos hidrelétricos passa por várias etapas, iniciando-se com a elaboração de Estudos de Inventário Hidrelétrico de bacias hidrográficas, passando por um estudo de viabilidade para cada barragem e, em seguida, pelo Estudo de Impacto Ambiental (EIA/RIMA) e audiência pública, do licenciamento ambiental (Figura 1) (Fearnside, 2014, World Bank, 2008). Os Estudos de Inventário Hidrelétrico de bacias hidrográficas são realizados pela ANEEL através de empresas por ela autorizadas, e, também, através da Empresa de Pesquisa Energética.

Esses inventários contemplam uma Avaliação Ambiental Integrada (AAI), cujo objetivo principal é avaliar a capacidade dos meios natural e antrópico para receber o conjunto de aproveitamentos hidrelétricos. Constata-se, no entanto, que tais avaliações foram realizadas apenas considerando um cenário de longo prazo, inicialmente até 2030 (Brasil, 2007a).

O licenciamento ambiental federal de hidrelétricas no Brasil geralmente tem início concomitantemente à etapa de elaboração dos estudos de viabilidade de barragem, e, é caracterizado por apresentar um sistema trifásico dividido em: licença prévia - definição quanto 
à viabilidade ambiental do empreendimento a partir da apresentação do EIA; licença de instalação - autorização do início das obras; e licença de operação - autorização do funcionamento da atividade. Os órgãos ambientais podem ainda solicitar estudos e informações adicionais durante o processo de licenciamento, para subsidiar as decisões a serem tomadas (Bragagnolo et al., 2017).

É importante ressaltar que enquanto a AAI tem por atribuição avaliar os efeitos do conjunto de empreendimentos associados a uma bacia hidrográfica sobre o meio ambiente, os Estudos de Impacto Ambiental (EIA) avaliam apenas os impactos de um empreendimento específico isolado, deixando assim de analisar, em seu escopo, os potenciais efeitos cumulativos e sinergéticos que podem incidir em uma determinada região (Castro et al., 2013).

A partir da obtenção da licença prévia, a responsabilidade da implantação da UHE é passada ao empreendedor, através da realização de leilões. 0 empreendedor deve então conduzir os procedimentos inerentes às fases subsequentes, a começar pelo Projeto Básico com o respectivo detalhamento do estudo de viabilidade, e, posteriormente, o Projeto Executivo. Também cabe ao empreendedor contratar a empresa de consultoria ambiental que ficará encarregada de desenvolver o Projeto Básico Ambiental (PBA).

A Figura 1 retrata a multiplicidade de etapas existentes durante o ciclo de implantação de usinas hidrelétricas, quer seja no âmbito do planejamento da expansão energética ou do licenciamento ambiental, associando as fases aos estudos e procedimentos aplicáveis.

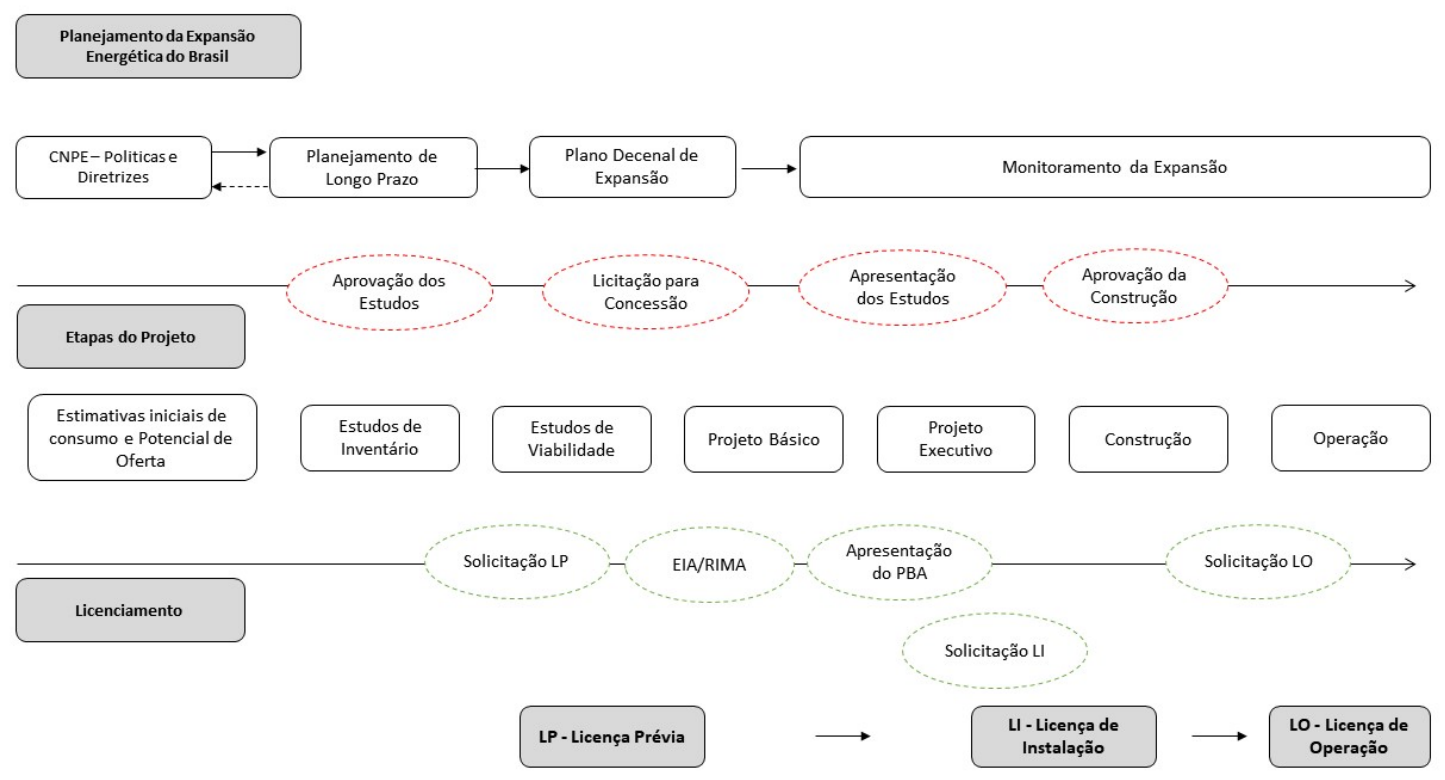

Figura 1 - Etapas do projeto de Hidrelétricas (Licenciamento X Planejamento de Longo Prazo) (Brasil, 2016, Santos \& Souza, 2011)

Segundo a EPE, a necessidade do planejamento estratégico e da avaliação periódica de desempenho socioambiental, ao longo do ciclo de vida das hidrelétricas, suscita a utilização de metodologia única que possa ser utilizada nas diferentes etapas do empreendimento, permitindo dessa forma incrementar a governança e transparência no desempenho dos indicadores socioambientais (Brasil, 2012b).

O presente artigo tem por objetivo identificar e avaliar a utilização de indicadores de desempenho socioambientais, no âmbito do planejamento estratégico federal, avaliando sua aplicação ao longo do relatório e analisar se os indicadores são integrados durante as diferentes fases empreendimentos hidrelétricos, desde o planejamento da matriz energética brasileira ao licenciamento ambiental, desenvolvidos nas etapas do projeto de usinas hidrelétricas. 


\section{METODOLOGIA}

Para realizar a identificação e avaliação da utilização de indicadores socioambientais, no planejamento estratégico brasileiro, foram realizadas buscas a partir nos sites das instituições públicas responsáveis pelo planejamento estratégico das hidrelétricas, com foco no levantamento das legislações e metodologias de avaliação de desempenho socioambiental.

Através do PDE, foram identificadas as principais metodologias de avaliação de desempenho socioambiental que subsidiam as tomadas de decisão de implantação de usinas hidrelétricas. As análises de desempenho do planejamento estratégico são realizadas conforme as diretrizes estabelecidas nas seguintes notas técnicas: NT DEA 17/12 - Metodologia para Avaliação Socioambiental de Usinas Hidrelétricas (Brasil, 2012b), DEA 19/12 - avaliação socioambiental integrada para projetos de energia (Brasil, 2012a), NT 015/17 - Análise socioambiental das fontes energéticas do PDE 2026 energia (Brasil, 2017a), NT 026/2018 - Análise socioambiental das fontes energéticas do PDE 2027 (Brasil, 2018a) e NT 012/2019 - Análise socioambiental das fontes energéticas do PDE 2029 (Brasil, 2019a).

Adicionalmente, foi realizada busca em sites de periódicos acerca dos artigos científicos, que avaliam os estudos do PDE e sobre indicadores de desempenho socioambiental de hidrelétricas no planejamento estratégico brasileiro.

Para avaliação dos indicadores, foram selecionados os relatórios do PDE referentes aos anos de 2021-2024, 2026, 2027 e 2029, pois esses foram os PDEs elaborados após a emissão da NT DEA 17/12 e introdução da respectiva metodologia de avaliação socioambiental de usinas hidrelétricas. Os indicadores foram avaliados com relação ao meio que pretendiam avaliar: meio físico, meio biótico ou meio socioeconômico; as unidades: se tratavam de indicadores relativos ou absolutos; bem como com relação à sua manutenção e/ou alteração nos estudos ao longo dos anos.

\section{RESULTADO E DISCUSSÃO}

O PDE possui metodologias específicas e dinâmicas que se utilizam de indicadores de avaliação de aspectos socioambientais, definidos por Notas Técnicas específicas, as quais acomodam alguns incrementos ao longo dos anos. A Nota Técnica 21/10 subsidiou a elaboração da avaliação da sustentabilidade socioeconômica e ambiental de Usinas Hidrelétricas e Linhas de Transmissão dos PDEs 2019 e 2020. A NT supracitada introduziu o conceito de sustentabilidade na avaliação desses empreendimentos, e, desenvolveu Índices de Sustentabilidade a fim de identificar e avaliar os impactos provocados pelas implantações de UHE e LT, nos âmbitos ambiental e socioeconômico (Brasil, 2010).

Junto ao PDE 2021, por sua vez, foram incorporadas as Notas Técnicas DEA 17/12 - avaliação socioambiental específica de hidrelétricas, a DEA 18/12 - referente à avaliação processual das usinas hidrelétricas e a DEA 19/12 - prevê uma avaliação socioambiental integrada para projetos de energia no Brasil. Todas foram publicadas em dezembro de 2012 (Brasil, 2012a, 2012b, 2012c). A DEA 19/12 prevê a avaliação apenas qualitativa, com destaque aos temas ambientais associados aos projetos e as possíveis interferências entre projetos, e os resultados são apresentados por região geográfica do país.

A NT 17/12, assim como a metodologia (NT 21/10) utilizada nos PDEs 2019 e 2020, é composta por três índices: impactos ambientais, socioeconômicos e benefícios socioeconômicos. Porém, alguns indicadores utilizados na versão anterior do PDE foram suprimidos e outros agrupados, sendo assim cada índice conta com apenas três indicadores nessa nova metodologia. Segundo a EPE, os indicadores foram escolhidos em função da relevância e da disponibilidade de dados para o cálculo (Brasil, 2012b).

É possível identificar que os PDEs elaborados nos anos subsequentes (PDEs 2022, 2023 e 2024) foram subsidiados pelos documentos acima mencionadas. Contudo, a partir de 2017, a parte referente à análise socioambiental específica para hidrelétricas, embora ainda estivesse de acordo com os parâmetros definidos pela DEA 17/12, passou a ser preparada em Notas Técnicas particulares para cada PDE. As NTs particulares contemplam, não apenas a análise socioambiental da oferta de energia elétrica, mas também de petróleo, gás natural e biocombustíveis. Nesse contexto, nas últimas edições do Plano Decenal para Expansão de Energia, foram emitidas as NT 015/17 - Análise socioambiental das fontes energéticas do PDE 2026, NT 026/2018 - Análise socioambiental das fontes energéticas do PDE 2027 e NT 012/2019 - Análise socioambiental das fontes energéticas do PDE 2029.

Houve também uma revisão da metodologia de avaliação processual quando da elaboração do PDE 2027, contudo a alteração realizada foi apenas com relação aos prazos adotados, os quais foram atualizados de acordo com a nova Nota Técnica EPE 027/18 (Brasil, 2018c).

A DEA 19/12, que se refere à avaliação socioambiental integrada, segue sendo utilizada como base e permeia todos os PDEs elaborados a partir de sua emissão.

A Tabela 1 apresenta as Nota Técnicas, metodologias, indicadores e respectivas características identificadas para a Etapa de planejamento estratégico de energia brasileiro. 
Tabela 1 - Etapa do Planejamento Estratégico (Política Energética) - Metodologias X Indicadores X Características.

\begin{tabular}{l|l}
\hline \multicolumn{1}{c|}{ Estudos } & \multicolumn{1}{c}{ Indicadores } \\
\hline & Indicadores Ambientais \\
& (a) Área alagada: área do reservatório/potência instalada da UHE; \\
& (b) Perda de vegetação: área de vegetação alagada e suprimida para implantação da UHE; \\
& (c) Trecho de rio alagado: trecho de rio a ser alagado para formação do reservatório; \\
& (d) Interferência em UC: distância entre a UHE e a UC, tipo de UC afetada; \\
& (e) Interferência em APCB distância entre a UHE e a APCB, tipo de APCB afetada \\
Indicadores Socioeconômicos
\end{tabular}

(f) População afetada: número de pessoas atingidas pela formação do reservatório;

(g) Interferência em TI: distância entre a UHE e a TI afetada, \% afetado da TI;

(h) Interferência em assentamentos do INCRA:

interferência da UHE em assentamentos do INCRA, \% afetado do assentamento;

(i) Interferência na infraestrutura: número de pessoas atraídas pela implantação da

UHE/população residente no(s) município(s) de apoio às obras;

NT 21/10 - avaliação da sustentabilidade socioeconômica e ambiental de UHE e LT.

(j) Potencial de empregos para a população local: população desocupada dos municípios atingidos/PEA dos municípios atingidos;

(l) Interferência em áreas urbanas: tipo de interferência em área urbana;

(m) Interferência na circulação e comunicação regional: tipo de interferência do

empreendimento na circulação e comunicação regional;

(n) Impacto temporário na arrecadação municipal:

ISS previsto para os municípios da casa de força e do canteiro de obras/soma das receitas orçamentárias dos municípios que vão receber o ISS;

(o) Impacto permanente na arrecadação municipal: compensação financeira prevista para os municípios/soma das receitas orçamentárias dos municípios que vão receber a compensação financeira;

(p) Perda de área produtiva: área produtiva alagada/área produtiva do(s) município(s) atingido(s).

NT 17/12 - Avalição socioambiental de usinas hidrelétricas

Impactos Ambientais: (a) perda de vegetação nativa, (b) transformação de ambiente lótico em lêntico, (c) interferência em unidade de conservação;

Impactos Socioeconômicos: (d) população afetada, (e) interferência em terra indígena (f) interferência na infraestrutura;

Benefícios Socioeconômicos: (g) geração de empregos, (h) incremento temporário na arrecadação municipal (ISS), (i) incremento permanente na arrecadação municipal (compensação financeira).
Total de Indicadores: 15

Total de Indicadores: 15

Meio Físico: 2 (a,c)

Meio Biótico: 3 (b, d, e)

Meio Socioeconômico: 10 (f, g, h, i, j, l,

m, n, o, p)

Absoluto: 5 (b, c, d, e, f)

Relativo: 10 (a, g, h, i, j, l, m, n, o, p)

OBS: Define Índices de

Sustentabilidade, a partir do resultado

da média dos indicadores das

dimensões ambiental e

socioeconômica, em cinco classes:

(Muito Alta[ $>0,8 \mathrm{e} \leq 1,0]$, Alta[ $>0,6 \mathrm{e}$

$\leq 0,8]$, Média[ $>0,4$ e $\leq 0,6]$, Baixa[ $>0,2$

$\mathrm{e} \leq 0,4]$, Muita Baixa[ $\leq 0,2])$. A classe

média sustentabilidade foi definida

como o crivo mínimo para um projeto

compor o plano de expansão. Os

dados apresentados nos PDEs

consistem no resultado final das UHEs

por bacia. Incorporada nos PDEs 2019 e 2020.

\section{Total de Indicadores: 9}

Meio Físico: 1(b)

Meio Biótico: 2 (a.c)

Meio Socioeconômico: 6 (d, e, f, g, h, i)

Absoluto: 6 (a, b, c, d, e, g)

Relativo: 3 (f, h, i)

OBS: Indicadores passaram a ser

tratados de acordo com o seu

potencial de impacto negativo ou

positivo (benefício). Para indicadores

negativos, $[0]=$ maior potencial de

impacto e [1] = menor potencial de

impacto, para indicadores de

benefício, a relação é inversa. Os

dados apresentados nos PDEs

consistem no resultado final do total

de UHEs do plano. Incorporada a partir do PDE 2021.

Prazos estudos de viabilidade (ANEEL): 37 meses

Prazos Licenciamento ambiental

- 12 meses emissão de TR

- 24 meses elaboração de EIA/RIMA

- 12 meses obtenção de LP

Prazos adicionais: tratativas para projetos com interferências em UCs (24 meses) e Tis (36 meses), atendimento a demandas judiciais (12 meses).

\section{Recursos Hídricos:}

(a) disponibilidade hídrica.

Biodiversidade Aquática:

(b) Transformação de ambiente lótico em lêntico; (c) Impactos no ecossistema marinho.

Vegetação Nativa:

(d) Perda de vegetação nativa.

Áreas Protegidas:

(e) Interferência em UC; (f) Interferências em APP.

Paisagem:

NT 19/12 - Análise socioambienta integrada (g) Interferências em áreas com potencial turístico; (h) Impacto visual.

Qualidade do Ar:

(i) Queimadas; (j) Emissões atmosféricas.

Populações Indígenas:

(1) Interferência em TI

Organização Territorial:

(m) População afetada; (n) Interferência em núcleos urbanos e rurais; (o) Interferência na circulação e comunicação; (p) Interferência na infraestrutura; (q) Interferências ou mudanças no uso do solo.

Questão Fundiária:

(r) Problemas de regularização fundiária.
Incorporada a partir do PDE 2021.

Estima o ano recomendado da

entrada em operação de cada um dos projetos hidrelétricos em estudo.

Total de Indicadores: 17 . Chamados

de "interferências" no documento. Por se tratar de uma análise integrada, apenas 10 se aplicam a UHEs.

Meio Físico: 3 (a, i, j)

Meio Biótico: 5 (b, c, d, e, f)

Meio Socioeconômico: 9 (g, h, l, m, n, o, p, q, r)

OBS: Incorpora a metodologia de avalição integrada de indicadores qualitativos a partir do PDE 2021. Os resultados referentes a análise socioambiental integrada são apresentados dentro dos PDEs e não em NTs separadas. Por não haver uma definição quanto às métricas e características dos indicadores, não foi possível classifica-los em relativos ou absolutos. 


\begin{tabular}{|c|c|c|}
\hline Estudos & Indicadores & Característica \\
\hline \multirow{2}{*}{$\begin{array}{l}\text { NT DEA 015/17 - Análise } \\
\text { socioambiental das fontes energéticas } \\
\text { do PDE } 2026\end{array}$} & \multirow{6}{*}{$\begin{array}{l}\text { Impactos Ambientais: (a) Área alagada; (b) Área alagada por potência instalada; (c) } \\
\text { Perda de vegetação nativa; (d) Perda de vegetação nativa por MW; (e) Transformação do } \\
\text { ambiente lótico em lêntico (km); (f) № de UHEs com interferência em UC de proteção } \\
\text { integral; (g) № de UHEs com interferência em UC de uso sustentável. } \\
\text { Impactos Socioeconômicos: (h) População diretamente afetada; (i) População } \\
\text { diretamente afetada por MW;(j) Interferência na infraestrutura (população } \\
\text { atraída/população dos municípios); (l) № de UHEs que interferem em quilombos; (m) № } \\
\text { de UHEs que interferem diretamente em TI; (n) № de UHEs situadas até } 40 \text { km de TI na } \\
\text { Amazônia Legal e } 15 \text { km nas demais regiões; } \\
\text { Benefícios Socioeconômicos: (o) Empregos diretos gerados no pico das obras; (p) } \\
\text { Empregos diretos gerados no pico das obras por MW; (q) Compensação financeira; (r) } \\
\text { Compensação financeira para os estados no decênio (R\$ milhões); (s) Compensação } \\
\text { financeira para os municípios no decênio; (t) ISS gerado nas obras no decênio. }\end{array}$} & Total de indicadores: 19 \\
\hline & & $\begin{array}{l}\text { Meio Físico: } 3 \text { (a, b, e) } \\
\text { Meio Biótico: } 4 \text { (c, d,f, g) }\end{array}$ \\
\hline \multirow{3}{*}{$\begin{array}{l}\text { NT EPE 026/18 - Análise } \\
\text { socioambiental das fontes energéticas } \\
\text { do PDE } 2027\end{array}$} & & $\begin{array}{l}\text { Meio Socioeconômico: } 12(\mathrm{~h}, \mathrm{i}, \mathrm{j}, \mathrm{l}, \mathrm{m} \text {, } \\
\mathrm{n}, \mathrm{o}, \mathrm{p}, \mathrm{q}, \mathrm{r}, \mathrm{s}, \mathrm{t})\end{array}$ \\
\hline & & $\begin{array}{l}\text { Absoluto: } 10 \text { (a, c, e, f, g, h, l, m, n, o) } \\
\text { Relativo: } 9 \text { (b, d, i, j, p, q, r, s, t) } \\
\end{array}$ \\
\hline & & OBS: NTs específicas aos PDEs \\
\hline $\begin{array}{l}\text { NT EPE- DEA - SMA 012/19 - Análise } \\
\text { socioambiental das fontes energéticas } \\
\text { do PDE } 2029\end{array}$ & & $\begin{array}{l}\text { emitidos a partir de } 201 \% \text { Tratam da } \\
\text { análise socioambiental de todas as } \\
\text { fontes energéticas. Usa como } \\
\text { referência para a parte de UHEs a } \\
\text { mesma estrutura de divisão de temas } \\
\text { e avaliação da NT } 17 / 12 \text {. Como as NTs } \\
\text { específicas não trazem as } \\
\text { características de cada indicador, foi } \\
\text { utilizada como referência a definição } \\
\text { da NT } 17 / 12 \text {. Os dados apresentados } \\
\text { nos PDEs consistem no resultado final } \\
\text { do total de UHEs do plano. }\end{array}$ \\
\hline $\begin{array}{l}\text { NT 27/18 - Avaliação processual de } \\
\text { usinas hidrelétricas }\end{array}$ & $\begin{array}{l}\text { - } 12 \text { meses emissão de TR (Caso afete TI - prazo não atribuído; caso afete UC de PI - } 24 \\
\text { meses) } \\
\text { - } 24 \text { meses elaboração de EIA/RIMA } \\
\text { - } 24 \text { meses obtenção de LP } \\
\text { Prazos adicionais: tratativas para projetos com em Tis ( } 36 \text { meses), atendimento a } \\
\text { demandas judiciais (12 meses). }\end{array}$ & $\begin{array}{l}\text { Alteração de prazos do licenciamento } \\
\text { ambiental }\end{array}$ \\
\hline
\end{tabular}

Fonte (BRASIL, MINISTÉRIO DE MINAS E ENERGIA, Empresa de Pesquisa Energética, 2010, 2011b, 2012a, c, b, 2017a, 2018a, b, 2019a)

Dessa forma, avaliando os relatórios do PDE referentes aos anos de 2021, 2022, 2023, 2024, 2026, 2027 e 2029, identifica-se uma variação nos indicadores de desempenho socioambiental utilizados para avaliar os empreendimentos. Destaca-se que, embora o PDE 2021 siga as diretrizes da NT 17/12 para definição do nível de impacto, na apresentação final dos indicadores pelo grupo de UHEs também são incorporados os indicadores da NT 21/10. À vista disso, o documento oferece elementos para comparação com edições anteriores (Brasil, 2012d, 2013, 2014, 2015b, 2017b, 2019b)

No que tange à definição de índices das diferentes Notas Técnicas, é possível observar que, enquanto a NT 19/12 apresenta índices de sustentabilidade para dar suporte às tomadas de decisão quanto a carteira de investimento em expansão de energia, a NT DEA 17/12 utiliza métricas e valores que classificam os projetos em níveis de impacto. De acordo com a metodologia apresentada na NT 17/12, os resultados dos indicadores devem ser expressos em um intervalo de 0 a 1 , sendo que para os indicadores de impacto negativo, " 0 " significa maior potencial de impacto e " 1 ", menor potencial de impacto. Para os indicadores de benefício, a relação é inversa. Por conseguinte, segundo a Nota Técnica, os indicadores de impactos e benefícios são avaliados separadamente e a média dos valores atribuídos aos indicadores deve corresponder ao cálculo do índice de impactos versus benefícios socioambientais de um projeto hidrelétrico. Posteriormente, os projetos de UHEs são agrupados, através da relação entre impactos e benefícios, de forma a propiciar uma avaliação socioambiental do conjunto de projetos para a tomada de decisão sobre a inclusão desses projetos na carteira de planejamento estratégico brasileiro (Brasil, 2012b). Entretanto, os valores atribuídos a cada indicador durante a análise não são divulgados ao público, ou seja, não é apresentado o valor do peso conferido a cada empreendimento ou um memorial do cálculo que foi realizado para tomada de decisão, conforme metodologia apresentada. Os valores são exibidos de forma conjunta para o grupo de hidrelétricas. Como exemplo, podemos citar o indicador "área alagada", em que nos PDEs apenas é informada a área total alagada do conjunto de UHEs já definidas para o projeto de expansão, ao invés de divulgar os valores que levaram à indicação daquele grupo de projetos para expansão do setor.

Para levantamento dos dados necessários a consolidação dos indicadores são utilizadas diferentes fontes como, IBGE, Receita Federal, e o SISA. O SISA é um Sistema de Informações Socioambientais das UHEs em desenvolvimento, implantado pela EPE e alimentado, principalmente, pelos empreendedores. Contudo, um dos desafios enfrentados, é que como nem sempre ocorre a alimentação periódica do SISA, muitas vezes as informações levantadas são baseadas em dados dos estudos de inventário hidrelétrico, o qual possui amplitude regional e aborda o conjunto de aproveitamentos de uma bacia. Sendo assim, a qualidade desses dados não é tão precisa quanto a de dados dos estudos de impacto ambiental (EIA) (Brasil, 2012b).

Com relação aos PDEs 2026, 2027 e 2029, ainda que esses sejam apresentados por Notas Técnicas específicas, elaboradas para cada um dos PDEs (NT 015/17, NT 026/2018 e NT 012/2019), estes também 
não explicitam os dados para cada empreendimento. Estes PDE incorporam alguns indicadores que não foram levados em consideração em PDEs anteriores, o agrupamento desses ocorreu nos mesmos índices definidos na NT DEA 17/12 (impacto ambiental, impacto socioeconômico e benefícios socioeconômicos). A mesma metodologia também foi utilizada para definição das métricas e fonte dos indicadores. As características e métricas dos indicadores definidos pela NT 17/12 estão apresentados na Tabela 2.

Tabela 2 - Métricas dos indicadores definidos pela NT DEA 17/12.

\begin{tabular}{|c|c|c|}
\hline Indicador & Característica & Valores \\
\hline \multicolumn{3}{|c|}{ Indicadores de Impacto Ambiental } \\
\hline \multirow{2}{*}{ Perda de Vegetação Nativa } & \multirow{2}{*}{$\begin{array}{l}\text { Total de área de vegetação nativa alagada para a } \\
\text { formação do reservatório. }\end{array}$} & $\begin{array}{l}<400 \mathrm{~km}^{2}: \text { distribuídos no intervalo de nota } 1 \text { a } 0 \\
\text { conforme equação linear }\end{array}$ \\
\hline & & $=\mathrm{ou}>400 \mathrm{~km}^{2}:$ nota 0 \\
\hline \multirow{5}{*}{ Interferência em UC (P.I. ou U.S.) } & \multirow{5}{*}{$\begin{array}{l}\text { Localização em relação à unidade, sua zona de } \\
\text { amortecimento e do grupo de UC que interferem } \\
\text { (proteção integral ou uso sustentável) }\end{array}$} & Fora de UC e de zona de amortecimento: nota 1 \\
\hline & & $\begin{array}{l}\text { Localizada em zona de amortecimento de UC de U.S: } \\
\text { nota } 0,75\end{array}$ \\
\hline & & $\begin{array}{l}\text { Localizada em zona de amortecimento de UC de P.I: } \\
\text { nota } 0,5\end{array}$ \\
\hline & & Localizada em UC de U.S: nota 0,25 \\
\hline & & Localizada em UC de P.I: nota 0 \\
\hline \multirow{2}{*}{$\begin{array}{c}\text { Transformação de ambiente lótico em } \\
\text { lêntico }\end{array}$} & \multirow{2}{*}{$\begin{array}{c}\text { Extensão do trecho de rio no corpo principal e seus } \\
\text { principais afluentes que serão alagados para a formação } \\
\text { do reservatório }\end{array}$} & $\begin{array}{l}\text { <300km: distribuídos no intervalo de nota } 1 \text { a } 0 \\
\text { conforme equação linear }\end{array}$ \\
\hline & & $=$ ou $>300 \mathrm{~km}:$ nota 0 \\
\hline \multicolumn{3}{|c|}{ Indicadores de Impacto Socioeconômicos } \\
\hline \multirow[t]{2}{*}{ População afetada } & \multirow[t]{2}{*}{ População total afetada pela formação do reservatório } & $\begin{array}{l}<20.000 \text { : distribuídos no intervalo de nota } 1 \text { a } 0 \\
\text { conforme equação linear }\end{array}$ \\
\hline & & $=$ ou > 20.000: nota 0 \\
\hline \multirow{3}{*}{ Interferência em TI } & \multirow{3}{*}{$\begin{array}{l}\text { Percentual da TI afetado ou distância do } \\
\text { empreendimento em relação às TIs. }\end{array}$} & Não afeta território de TI: nota 1 \\
\hline & & Afeta indiretamente TI: nota 0,5 \\
\hline & & Afeta diretamente território de TI: nota 0 \\
\hline \multirow{2}{*}{ Interferência na infraestrutura } & \multirow{2}{*}{$\begin{array}{c}\text { População atraída x população residente no município de } \\
\text { apoio às obras: } i=3 \times n^{o} \text { empregos gerados } / \text { pop. } \\
\text { municípios de apoio }\end{array}$} & $\begin{array}{l}<100 \% \text { : distribuídos no intervalo de nota } 1 \text { a } 0 \\
\text { conforme equação linear }\end{array}$ \\
\hline & & $=$ ou $>100 \%:$ nota 0 \\
\hline \multicolumn{3}{|c|}{ Indicadores de Benefícios Socioeconômicos } \\
\hline \multirow[t]{2}{*}{ Empregos gerados } & \multirow{2}{*}{$\begin{array}{l}\text { Número de empregos diretos gerados pela construção } \\
\text { do empreendimento }\end{array}$} & $\begin{array}{l}<5.000 \text { : distribuídos no intervalo de nota } 0 \text { a } 1 \\
\text { conforme equação linear }\end{array}$ \\
\hline & & $=$ ou $>5.000:$ nota 1 \\
\hline \multirow{2}{*}{$\begin{array}{l}\text { Incremento temporário na arrecadação } \\
\text { municipal }\end{array}$} & \multirow{2}{*}{$\begin{array}{c}\text { Razão entre o ISS gerado durante a construção e o } \\
\text { somatório das receitas dos municípios nos quais o } \\
\text { imposto será recolhido: } i=\text { arrecadação anual de ISS } \\
\text { durante construção/soma da receita orçamentária dos } \\
\text { municípios }\end{array}$} & $\begin{array}{l}<30 \% \text { : distribuídos no intervalo de nota } 0 \text { a } 1 \\
\text { conforme equação linear }\end{array}$ \\
\hline & & $=$ ou $>30 \%:$ nota 1 \\
\hline \multirow[t]{2}{*}{$\begin{array}{l}\text { Incremento permanente na arrecadação } \\
\text { municipal }\end{array}$} & \multirow{2}{*}{$\begin{array}{l}\text { Relação entre a compensação financeira estimada para } \\
\text { os municípios atingidos e a receita total desses } \\
\text { municípios: } i=\text { soma da compensação fin. dos } \\
\text { municípios/soma da receita orçamentária }\end{array}$} & $\begin{array}{l}<15 \% \text { : distribuídos no intervalo de nota } 0 \text { a } 1 \\
\text { conforme equação linear }\end{array}$ \\
\hline & & $=$ ou $>15 \%:$ nota 1 \\
\hline
\end{tabular}

Fonte (Brasil, 2012b)

Embora o Plano Decenal de Expansão de Energia (PDE) busque definir os projetos para o atendimento à demanda energética do país e não analise somente empreendimentos hidrelétricos; as questões socioambientais são consideradas para seleção das hidrelétricas, que estejam no portfólio da expansão. Considerando que as métricas e fontes para avaliação de indicadores socioambientais estejam definidas na Nota Técnica DEA 17/12, mesmo os PDEs 2026, 2027, 2029, que possuem Nota Técnicas específicas para as avaliações socioambientais 
das fontes energéticas divulgadas nos estudos do PDE, não apresentam as informações dos indicadores por usina hidrelétrica, e sim pelo conjunto de usinas previsto na implantação do (PDE).

Depreende-se que não se pode verificar como os valores levantados durante a análise foram ponderados na tomada de decisão da seleção de hidrelétricas, além do fato dos indicadores não poderem ser comparados ao longo do tempo, uma vez que estes são avaliados por empreendimento nas etapas de instalação e operação do empreendimento. Assim como se observa que o fato de os dados não serem divulgados por hidrelétrica permite que UHEs de baixo desempenho socioambiental sejam compensadas por UHEs, que possuam melhor eficiência no desempenho ambiental, uma vez que os índices são estabelecidos para o conjunto de hidrelétricas (Fearnside, 2014, 2015a, 2015b, 2016, 2017; Ritter et al., 2017).

As figuras apresentadas, a seguir, ilustram os valores e as tendências identificadas entre os indicadores socioambientais utilizados nos diferentes PDEs analisados. Para possibilitar as análises, os gráficos foram elaborados de acordo com as unidades de representação, ou seja, os indicadores com unidades homogêneas foram agrupados em conjunto em um mesmo gráfico, independente se de cunho ambiental ou socioeconômico.

A Figura 1 refere-se aos indicadores de impacto ambiental, representado pela unidade absoluta de $\mathrm{km}^{2}$. Ao analisá-la, constata-se que, embora esteja previsto o indicador de impacto ambiental “transformação do ambiente aquático (Lótico em lêntico)" na NT DEA 17/12, os PDEs nos anos de 2021 a 2024 não apresentam tal informação. Os valores para esse indicador apenas passaram a ser quantificados a partir do PDE 2026. Adicionalmente, é possível notar que, embora todos os PDEs analisados apresentem dados referentes ao indicador "área alagada", este indicador não é contemplado de forma explicita pela NT 17/12.

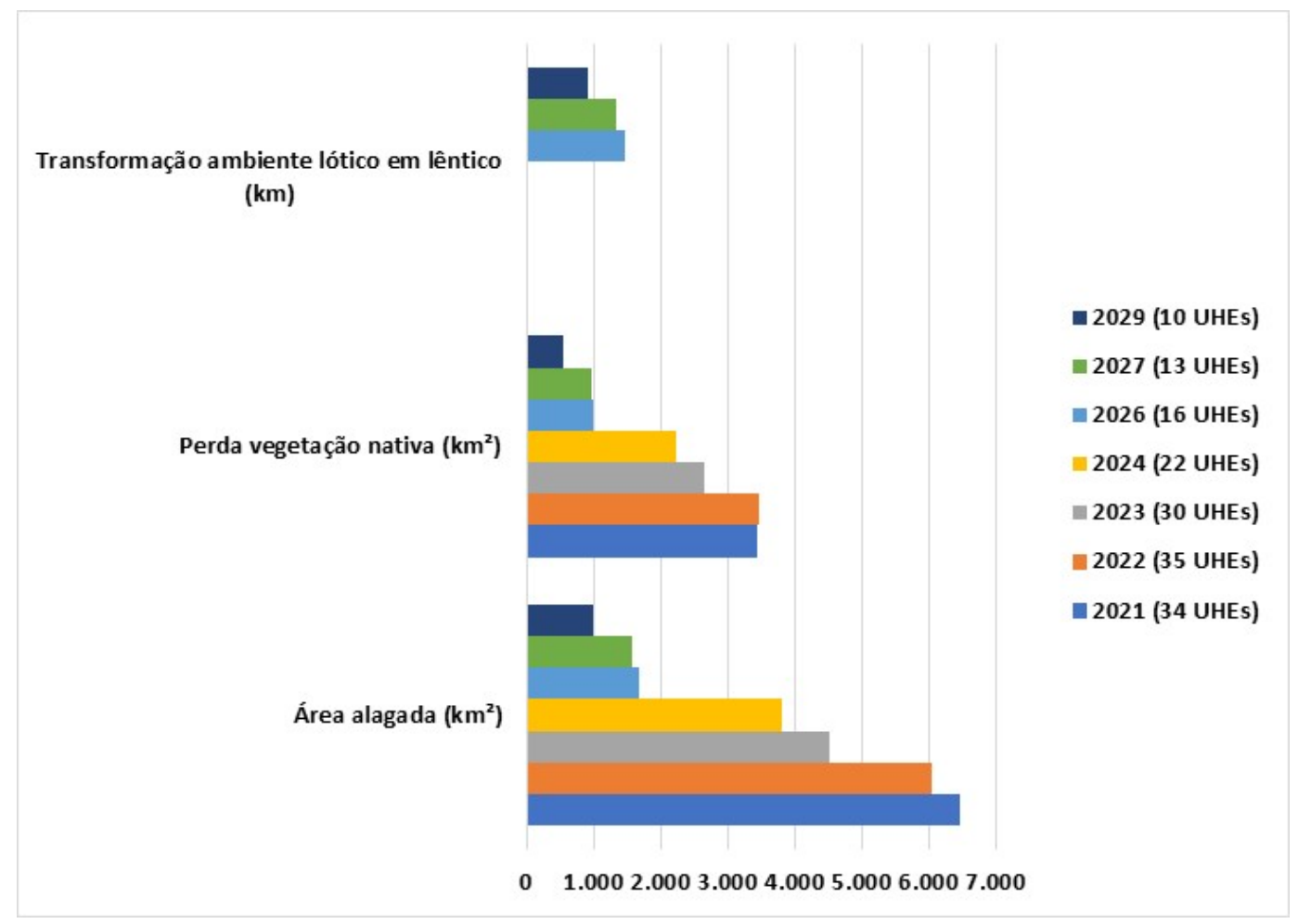

Figura 2 - Indicadores de Impacto Ambiental

(Figure 2 - Environmental Impact Indicators)

A Figura 2 apresenta indicadores que utilizam unidade numérica absoluta e representa interferências em áreas de proteção, sejam eles ambientais como interferência em Unidades de Conservação, ou sociais como interferência em terras de povos tradicionais. Pode-se observar que no PDE 2024 foi adicionado um novo indicador, com relação aos apresentados nos anos anteriores, a saber: № de UHEs situadas até $40 \mathrm{~km}$ de TI na Amazônia Legal e $15 \mathrm{~km}$ nas demais regiões. Fato esse ocorrido devido ao aumento de conflitos socioeconômicos relacionados a licenciamento de empreendimentos UHEs próximos a Terras Indígenas - TIs, interferência esta que se apresenta como 
um dos principais motivos para indeferimento de pedidos de licença prévia de UHEs. Os PDEs dos anos anteriores incorporavam como indicador apenas № de UHEs com interferência direta em TIs.

Conforme o §3ำ do artigo 231 da Constituição Federal de 1988, a instalação de projetos em terras indígenas só pode ser efetivada com a autorização do Congresso Nacional, ouvidas as comunidades indígenas. Segundo a EPE a falta de regulamentação deste artigo constitucional deixa em aberto as formas de compensação às comunidades indígenas atingidas e, considerando isso, atualmente não se prevê o aproveitamento hidrelétrico em TIs no horizonte de dez anos. Entretanto, no PDE de 2027, a EPE indica que mais de $50 \%$ do potencial hidrelétrico do país sobrepõem TIs. Ainda que as questões referentes ao aproveitamento dos recursos hídricos nas terras indígenas tenham a perspectiva do longo prazo, o desafio que esse cenário representa para a expansão faz com que o tema seja considerado relevante e decisivo para sua definição mesmo no planejamento estratégico, realizado pelo Plano Decenal de Expansão da Energia - PDE (Brasil, 2018c; Fearnside, 2015a).

O plano de expansão de expansão de energia, PDE 2027 aponta ainda que, em decorrência aos crescentes desafios apresentados com relações a aproveitamento de recursos hidrelétricos em terra indígenas, a implantação de projetos de UHEs com sobreposição a TIs havia sido retirada do planejamento, levantando o cenário como tema relevante e decisivo para definições no horizonte decenal (Brasil, 2018c).

Por outro lado, de acordo com o PDE 2029, embora, dentre as 10 UHEs planejadas para o decênio, nenhuma seja sobreposta a terras indígenas, uma questão importante a ser considerada é que os projetos das regiões Norte e Centro-Oeste estão situados nas proximidades desses territórios.

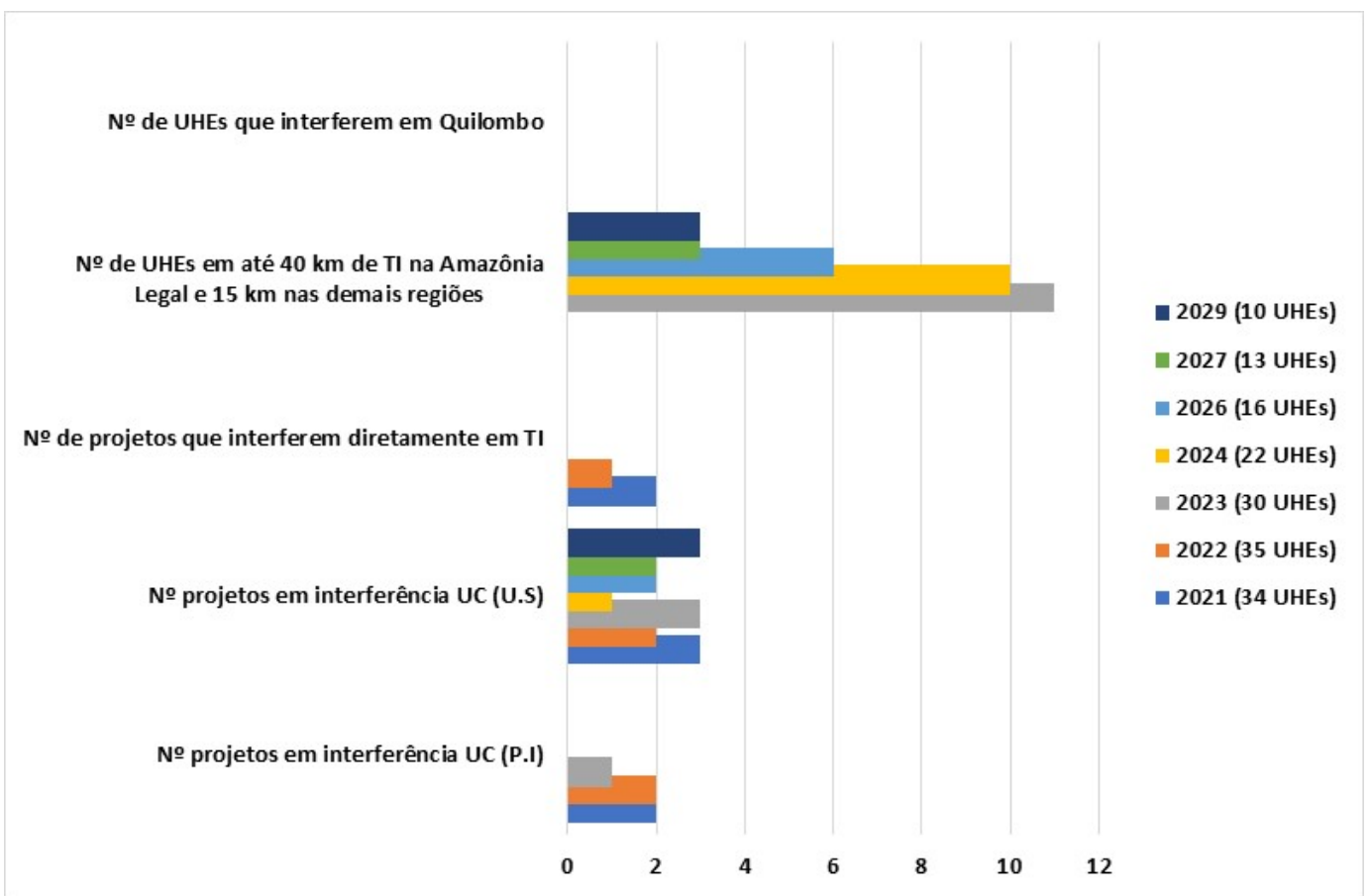

Figura 3 - Indicadores que apresentam interferência em Unidades de Conservação ou em terras de povos tradicionais. Legenda: P.I - Proteção Integral; U.S - Uso Sustentável

(Figure 3 - Indicators that present interference in Conservation Units or in traditional peoples' lands. Legend: P.I Integral Protection; U.S - Sustainable Use)

No PDE 2026, além do indicador adicionado no PDE 2024 (distância de TI), foram incorporados mais 2 indicadores aos antigos, a saber: (i) № de UHEs que interferem em Quilombo; (ii) Interferência na infraestrutura (população atraída / população dos municípios) (Figuras 3 e 4). Ressalta-se que nenhum dos empreendimentos previsto possuíam interferência com Quilombolas, o que explica a inexistência de valores no gráfico.

Na Figura 4, encontram-se apresentados os dados dos indicadores relativos, os quais comparam o impacto ambiental ou social com a potência gerada pelo empreendimento, estabelecendo uma avaliação de desempenho relativa à potência, buscando viabilizar uma comparação do desempenho dos projetos. Faz-se importante destacar que a NT 17/12 apenas prevê indicadores absolutos relativos aos temas: empregos gerados, população afetada e perda de vegetação. Dessa forma as métricas 
especificas dos indicadores de correlação referentes aos temas supracitados, não são contemplados pela Nota Técnica.

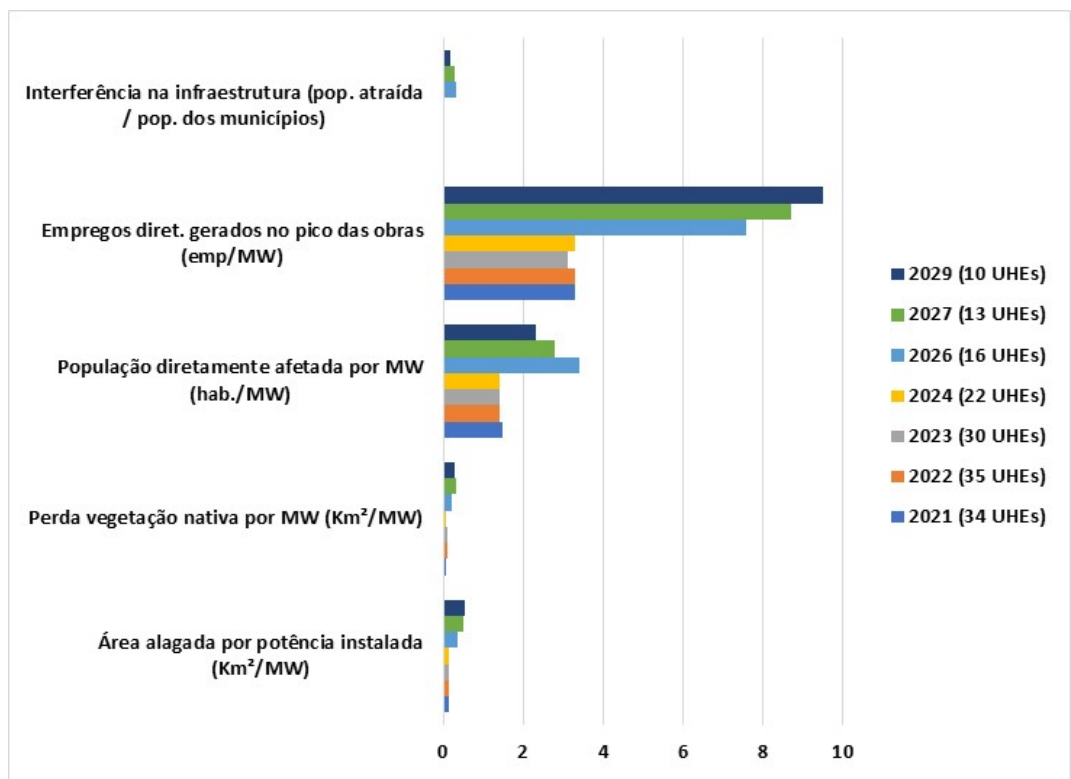

Figura 4 - Indicadores relativos

(Figura 4 - Indicadores de correlação)

Com relação aos demais indicadores socioeconômicos, é possível perceber que esses seguiram a mesma metodologia durante as diferentes Notas Técnicas, sendo apresentado assim valores para os mesmos indicadores ao longo dos últimos anos (Figuras 5 e 6). Porém identifica-se que o indicador (i) Compensação financeira para os estados, não estava inicialmente previsto na metodologia definida pela NT DEA 17/12. Apenas era contemplado o indicador de compensação financeira para os municípios.

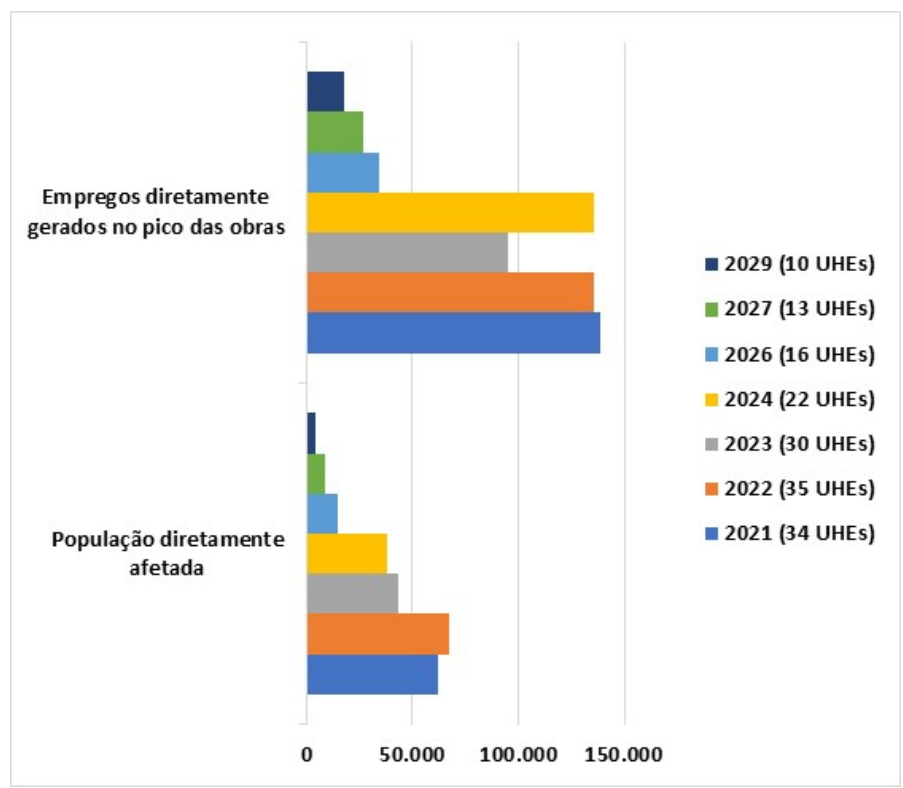

Figura 5 - Indicadores socioeconômicos (1)

(Figure 5 - Socioeconomic indicators (1)) 


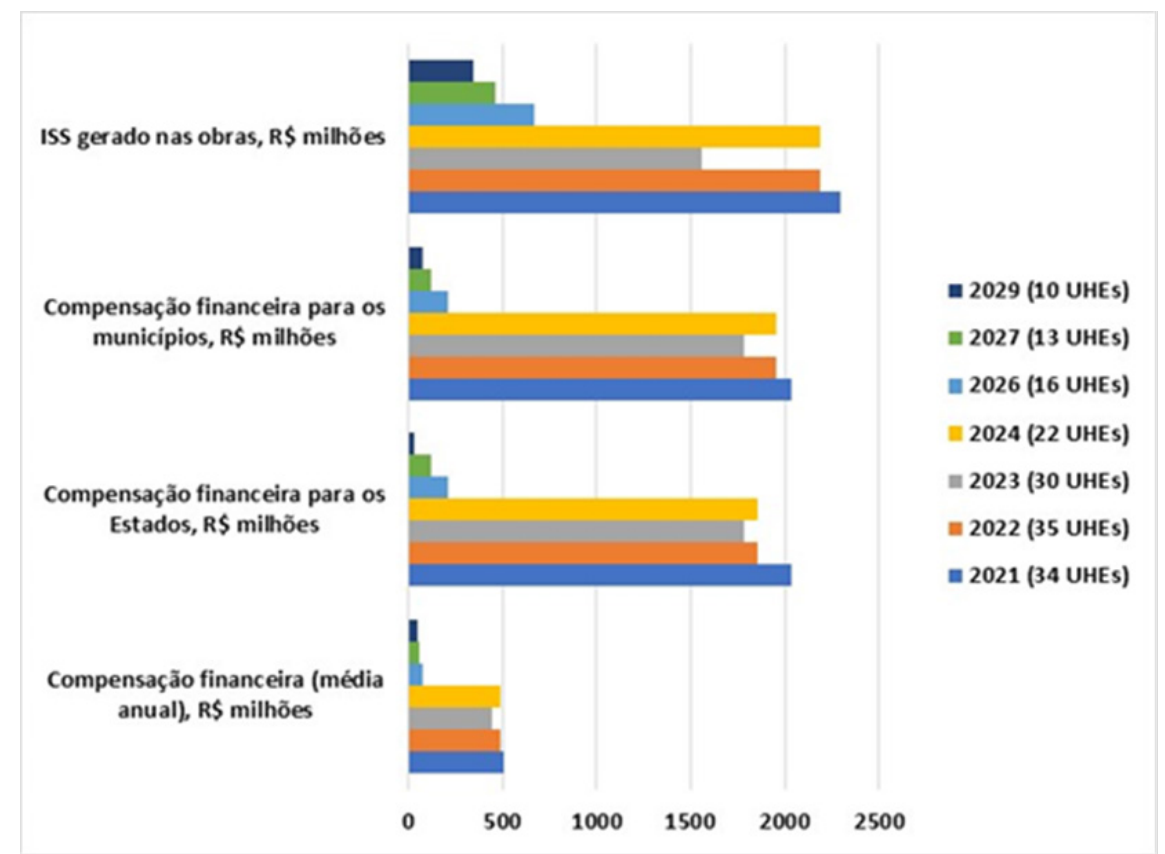

Figura 6 - Indicadores Socioeconômicos (2)

(Figure 6 - Socioeconomic indicators (2))

Além da variação entre os indicadores utilizados nas publicações dos PDEs ao longo dos últimos anos, os aspectos e impactos socioambientais das hidrelétricas são avaliados e autorizados em diferentes critérios, em distintas etapas do planejamento e do licenciamento, realizadas por distintos atores governamentais. Sendo estes aspectos e impactos essencialmente gerenciados e monitorados através do licenciamento ambiental.

É importante ressaltar que a avaliação de licenças ambientais da ANEEL, que ocorre na etapa de planejamento estratégico, se resume a avaliação do andamento do processo, ou seja, em qual fase se encontra o processo e a previsão início de operação. Não há a avaliação dos aspectos socioambientais e seus respectivos indicadores de desempenho, que são desenvolvidos apenas pelos estudos da EPE nesta etapa de planejamento inicial do projeto.

Durantes as fases de planejamento/concepção, instalação e operação, ocorre a avaliação dos impactos ou das medidas mitigadoras, nem sempre são identificados indicadores de desempenho dessas avaliações. Durante a primeira fase, de planejamento a caracterização é realizada através da Empresa de Pesquisa Energética (EPE), vinculada ao Ministério de Minas e Energia (MME). Durante a fase de licenciamento ambiental prévio à instalação, são realizados estudos ambientais, por exemplo os Estudos de Impacto Ambiental (EIA's), sendo sugeridos os programas básicos ambientais (PBA's).

Durante as fases de Instalação e operação dos empreendimentos, os controles dos aspectos socioambientais do empreendimento são desenvolvidos (monitorados e controlados) pela realização dos PBA's, cujos resultados são apresentados em relatórios semestrais de andamento dos referidos programas ambientais, sendo identificada utilização de indicadores de desempenho através destes programas, em alguns empreendimentos.

Apesar das avaliações de aspecto e impacto serem capitaneadas pelo IBAMA, pareceres de outras instituições, como FUNAI, ICMBio, IPHAN, Fundação Palmares, ANA, são necessários para a validação da avaliação socioambiental realizada pelo órgão ambiental federal - IBAMA (Brasil, 2015b).

O IBAMA e demais órgãos associados ao licenciamento também têm pequena participação na etapa de planejamento, resumindo-se apenas ao início do processo de licenciamento com a caracterização do empreendimento. Ou seja, o planejamento estratégico realizado pela EPE seleciona os projetos para a expansão da oferta de energia, inclusive sob os aspectos socioambientais, para o posterior encaminhamento destes empreendimentos as etapas seguintes com a atuação de atores como IBAMA, ANA e órgãos estaduais e municipais.

Sendo assim, na etapa de planejamento estratégico, os indicadores de desempenho socioambientais são desenvolvidos pela EPE, já na etapa seguinte de planejamento do projeto, os indicadores são desenvolvidos pelas consultorias ambientais (responsáveis pelos Estudos de Impacto Ambiental - EIAs) e contratadas pelos empreendedores. Os indicadores apresentados pelas 
consultorias ambientais são então chancelados pelo órgão regulador IBAMA, através da aprovação dos estudos ambientais e dos programas básicos ambientais de controle, monitoramento e mitigação dos aspectos identificados no EIA (Duarte et al., 2017; Sánchez, 2010). Os programas de controle e mitigação têm importância fundamental na consolidação do processo de planejamento ambiental, pois são os instrumentos de geração de dados de monitoramento ambiental ao longo do tempo, o que permite o acompanhamento da performance socioambiental dos empreendimentos. (Fearnside, 2015b).

Segundo o PDE 2029, a redução no número de UHEs previsto para expansão nos últimos anos, pode estar em parte ligada ao crescimento de outras fontes de energia, contudo, os desafios de caráter socioambiental têm influência direta nesse cenário. Tendo em vista que a maior extensão de áreas protegidas está localizada na região Amazônica, e que nessa região também se encontra parte expressiva do potencial hidrelétrico do país, a probabilidade de interferência na implantação de UHEs em terras indígenas e unidades de conservação é consideravelmente alta (Brasil, 2019a).

Outros fatores que potencializam os desafios no planejamento da expansão de UHEs são a falta de regulamentação dos dispositivos normativos relativos aos povos tradicionais, e a indefinição sobre encaminhamentos de UHEs com interferência em unidades de conservação (Brasil, 2019a).

O processo de implantação de uma usina hidrelétrica passa por várias etapas de estudos, análises e tomadas de decisões, realizadas por diferentes órgãos federais. Dessa forma, a não existência de uma sistemática integrada com disponibilização de banco de dados, torna a identificação dos indicadores de desempenho ambiental decorrentes dessas avaliações de impacto e da adoção das medidas mitigadoras, um grande desafio nas sucessivas tomadas de decisão dessa cadeia de planejamento e execução de um empreendimento hidrelétrico.

Em relação ao planejamento estratégico, segundo a EPE, um dos grandes desafios enfrentados no Plano Decenal de Expansão de Energia (PDE) tem sido considerar os critérios socioambientais na definição dos projetos hidrelétricos a serem implantados em todo o território nacional. Dessa forma, a EPE considera necessária a colaboração dos agentes empreendedores para a atualização contínua das informações sobre os projetos, ao longo do andamento dos estudos, de modo a contribuir para a consistência da avaliação socioambiental (Brasil, 2012d).

O empecilho na emissão de licenças ambientais para os empreendimentos hidrelétricos está na emissão da licença prévia, uma vez que exatamente nesta fase, há maior envolvimento do órgão na tomada de decisão da viabilidade socioambiental do empreendimento através da definição dos critérios técnicos dos estudos a serem realizados pelos empreendedores, pela elaboração de Termos de Referência para os EIA e a avaliação destes estudos pelo órgão ambiental para emissão da licença de instalação e suas respectivas medidas de controles e prevenção dos impactos ambientais (World Bank, 2008).

Estudos legislativos da câmara dos deputados, de julho de 2015, apontam como gargalos ao licenciamento ambiental, estudos extensos de baixa qualidade focados no diagnóstico; excesso de condicionante e falta de acompanhamento de sua efetividade; multiplicidade de atores com poderes discricionários; postergação de estudos e condicionantes em diferentes fases do projeto; ausência de dados e informações ambientais sistematizadas; excesso de atos normativos e a falta de estrutura e pessoal dos órgãos ambientais. (Hofmann, 2015).

Em suma, no que se refere à natureza e número de índices, foi possível observar que os indicadores de desempenho socioambiental do PDE dos anos de 2021 a 2024 foram divididos e avaliados conforme a Nota Técnica DEA 17/12, a qual prevê 3 indicadores de impacto ambiental, 3 indicadores de impacto socioeconômico e 3 indicadores de benefícios socioeconômicos.

Os PDEs 2026, 2027 e 2029, por sua vez, levaram em consideração 7 indicadores ambientais e 12 indicadores socioeconômicos, todos abordados pelas Notas Técnicas especificas, elaboradas para cada um dos PDEs (NT 015/17, NT 026/2018 e NT 012/2019). Embora para esses PDEs tenham sido adicionados indicadores socioambientais, que não foram levados em consideração em PDEs anteriores, os indicadores foram agrupados nos mesmos índices definidos NT DEA 17/12 (impacto ambiental, impacto socioeconômico e benefícios socioeconômicos), bem como seguiram a mesma metodologia de definição de valor de indicadores.

Dessa forma, identifica-se que apesar de terem ocorrido alterações nos indicadores socioambientais utilizados nos PDEs analisados, principalmente no que tange à adição ou ao incremento de alguns indicadores ao longo dos anos, a Empresa de Pesquisa Energética utiliza como metodologia base para avaliação socioambiental de UHEs a NT DEA 17/12 - Metodologia para Avaliação Socioambiental de Usinas Hidrelétricas. 
Os indicadores relativos à análise socioambiental integrada, abordados em todos os PDEs analisados, por sua vez, seguem as diretrizes da NT DEA 19/12, que prevê uma avaliação socioambiental integrada para projetos de energia no geral, não sendo específica para hidrelétricas. Portanto, considerando-se apenas os parâmetros utilizados para avaliação das UHEs, a NT supracitada elenca 10 interferências, como nomeados no documento: i) Transformação de ambiente lótico em lêntico; ii) Perda de vegetação nativa; iii) interferência em UC; iv) interferência em APP; v) interferência em TI; vi) População afetada; vii) Interferência em núcleos urbanos e rurais; viii) Interferência na circulação e comunicação; ix) Interferência na infraestrutura; ex) Interferências ou mudanças no uso do solo. Entretanto, conforme abordado anteriormente, os valores finais apresentados nos PDEs não contemplam o peso atribuído a cada empreendimento durante à análise qualitativa realizada para a tomada de decisão da inclusão dos empreendimentos hidrelétricos no plano decenal d expansão. Portanto a avaliação dos aspectos e impactos no longo prazo através de indicadores se apresenta diferente da abordagem de indicadores desenvolvidos nas fases subsequentes do licenciamento ambiental que consideram os dados por empreendimento hidrelétrico.

\section{CONCLUSÕES}

Diante da pesquisa realizada, identifica-se que o principal instrumento de avaliação de desempenho socioambiental dos empreendimentos hidrelétricos, durante a etapa de planejamento estratégico, são os estudos do Plano Decenal de Expansão de Energia - PDE, realizados pela EPE, e suas metodologias de avaliação socioambiental associadas e editadas através de notas técnicas. Ainda assim, de acordo com o instrumento de licenciamento ambiental vigente no Brasil, os PDEs não passam por um processo regulamentado de avaliação de impactos e sim cada projeto de construção de hidrelétrica em particular deve passar pelo próprio processo de licenciamento ambiental.

Mesmo considerando que o PDE pretende abordar a avalição da matriz brasileira por fonte energética, observa-se, que os indicadores de desempenho socioambientais utilizados nas etapas de planejamento estratégico não são integrados aos utilizados nas demais etapas, mesmo quando tratando do mesmo tema, por exemplo vegetação, do aspecto ambiental. Da mesma forma, não há retroalimentação das informações geradas durante as fases, subsequentes de planejamento do projeto, instalação e operação para com a fase de planejamento de longo prazo das UHE's.

Todavia, constata-se que, além de não haver clareza na divulgação dos cálculos com relação aos valores de indicadores socioambientais atribuídos à cada UHE quando da tomada de decisão para inserção dessas no plano de crescimento do setor, a metodologia de avaliação dos indicadores utilizada nos PDEs não foi capaz de antecipar conflitos com relação ao licenciamento de empreendimentos com influência em terras de povos tradicionais, dificultando o processo de priorização de empreendimentos viáveis em longo prazo

Acredita-se que a ausência de parâmetros objetivos para a definição da viabilidade ambiental e a dificuldade de integração da avaliação ambiental estratégica com os demais instrumentos ambientais afetem diretamente na efetividade do processo de licenciamento, bem como, no monitoramento a longo prazo. Em vista disso, hoje, há discussões no Congresso Nacional sobre diversas propostas de mudanças no instrumento de licenciamento, especialmente através da criação da Lei Geral do Licenciamento Ambiental - Projeto de Lei no 3.729/2004 e seus substitutivos.

Desafios de gerenciamentos nos empreendimentos hidrelétricos não se restringem apenas à área do reservatório e de influência direta do empreendimento. 0 regime de vazão do empreendimento pode alterar a vazão do rio e a condição de uso múltiplo da água na bacia hidrográfica como um todo, aumentando sobremaneira a importância na gestão dos impactos das usinas hidrelétrica e a necessidade de um planejamento estratégico bem embasado. É de suma importância que a participação do MME/EPE seja integrada aos órgãos de licenciamento ambiental, de forma a consolidar uma metodologia única que possibilite a sistematização de dados e avaliação periódica de desempenho socioambiental ao longo do tempo.

Ainda com relação à complexa dinâmica do processo de licenciamento, existe um crescente debate sobre a carência de uma avaliação ambiental estratégica que possibilite uma visão integrada dos empreendimentos previstos para cada região, através de avaliação sistêmica e abrangente que contemple efeitos cumulativos e sinérgicos de múltiplos projetos (Brasil, 2019a).

A utilização de indicadores sistêmicos e contínuos auxilia na sistematização e divulgação dos dados socioambientais de desempenho das UHE, gerados pelos empreendedores quando do cumprimento das exigências ambientais do licenciamento. Dessa forma, os órgãos reguladores 
viabilizam a avaliação e divulgação das informações de desempenho socioambiental das hidrelétricas de forma coesa e eficaz ao longo do tempo.

Além disso, a divulgação sistemática de dados de desempenho gera maior transparência na tomada de decisão da gestão compartilhada do uso da água, contribuindo na gestão dos aspectos ambientais em todo o ciclo, da concepção a desativação dos empreendimentos hidrelétricos. Inclusive, retroalimentado o planejamento de longo prazo do governo brasileiro.

Conclui-se que são utilizados os indicadores socioambientais nos ciclos de planejamento estratégico, porém não o utilizam de forma integrada e sistêmica aos indicadores do licenciamento ambiental para obtenção da avaliação de desempenho ao longo do ciclo de vida do empreendimento. Sendo, portanto, considerada a subutilização dos indicadores socioambientais para a comunicação do desempenho desses empreendimentos, assim como para a tomada de decisão do desempenho socioambiental ao longo do tempo, inviabilizando-se assim decisões racionais de alocação de recursos e soluções de problema de natureza socioambiental, associadas aos empreendimentos hidrelétricos.

\section{REFERENCIAS}

Bragagnolo, C., Carvalho Lemos, C., Ladle, R. J., \& Pellin, A. (2017). Streamlining or sidestepping? Political pressure to revise environmental licensing and EIA in Brazil. Environmental Impact Assessment Review, 65, 86-90. http://dx.doi.org/10.1016/j.eiar.2017.04.010.

Brasil. Ministério de Minas e Energia. (2007a). Manual de inventário hidroelétrico de bacias hidrográficas. Brasília: Ministério de Minas e Energia.

Brasil. Ministério de Minas e Energia. Empresa de Pesquisa Energética. (2007b). Matriz Energética Nacional 2030. Rio de Janeiro: EPE.

Brasil. Ministério de Minas e Energia. Empresa de Pesquisa Energética. (2010). Nota Técnica DEA 21/10: metodologia para avaliação da sustentabilidade socioeconômica e ambiental de UHE e LT. Rio de Janeiro: EPE.

Brasil. Ministério de Minas e Energia. Empresa de Pesquisa Energética. (2011a). PDE assegura expansão equilibrada da oferta energética. Rio de Janeiro: EPE. Recuperado em 3 de outubro de 2019, de http://legado.brasil.gov.br/noticias/infraestrutura/2011/12/pde-assegura-expansao-equilibrada-daoferta-energetica

Brasil. Ministério de Minas e Energia. Empresa de Pesquisa Energética. (2011b). Plano Decenal de Expansão de Energia 2020. Rio de Janeiro: EPE. Recuperado em 3 de outubro de 2019, de http://www.epe.gov.br/pt/publicacoes-dados-abertos/publicacoes/plano-decenal-de-expansao-deenergia-pde

Brasil. Ministério de Minas e Energia. (2012a). Nota Técnica DEA 19/12: metodologia para a análise Socioambiental Integrada. Brasília: Ministério de Minas e Energia.

Brasil. Ministério de Minas e Energia. Empresa de Pesquisa Energética. (2012b). Nota Técnica DEA 17/12: metodologia para Avaliação Socioambiental de Usinas Hidrelétricas. Rio de Janeiro: EPE. Recuperado em 3 de outubro de 2019, de http://www.epe.gov.br

Brasil. Ministério de Minas e Energia. Empresa de Pesquisa Energética. (2012c). Nota Técnica DEA 18/12: metodologia para Avaliação Processual de Usinas Hidrelétricas. Rio de Janeiro: EPE. Recuperado em 3 de outubro de 2019, de http://www.epe.gov.br

Brasil. Ministério de Minas e Energia. Empresa de Pesquisa Energética. (2012d). Plano Decenal de Expansão de Energia 2021. Rio de Janeiro: EPE. Recuperado em 3 de outubro de 2019, de http://www.epe.gov.br/pt/publicacoes-dados-abertos/publicacoes/plano-decenal-de-expansao-deenergia-pde

Brasil. Ministério de Minas e Energia. Empresa de Pesquisa Energética. (2013). Plano Decenal de Expansão de Energia 2022. Rio de Janeiro: EPE. Recuperado em 3 de outubro de 2019, de http://www.epe.gov.br/pt/publicacoes-dados-abertos/publicacoes/plano-decenal-de-expansao-deenergia-pde

Brasil. Ministério de Minas e Energia. Empresa de Pesquisa Energética. (2014). Plano Decenal de Expansão de Energia 2023. Rio de Janeiro: EPE.

Brasil. (2015a). Portaria Interministerial no 60 de 24 de Março de 2015. Estabelece procedimentos administrativos que disciplinam a atuação dos órgãos e entidades da administração pública federal em processos de licenciamento ambiental de competência do Instituto Brasileiro do Meio Ambiente e dos Recursos Naturais Renováveis-IBAMA. Diário Oficial [da] República Federativa do Brasil, Brasília. 
Brasil. Ministério de Minas e Energia. Empresa de Pesquisa Energética. (2015b). Plano Decenal de Expansão de Energia 2024. Rio de Janeiro: EPE. Recuperado em 3 de outubro de 2019, de http://www.epe.gov.br/pt/publicacoes-dados-abertos/publicacoes/plano-decenal-de-expansao-deenergia-pde

Brasil. Ministério de Minas e Energia. (2016). Metodologia para o desenvolvimento e implantação de projetos de usinas hidrelétricas sob o conceito de usinas-plataforma (pp. 182). Brasília: Ministério de Minas e Energia.

Brasil. Ministério de Minas e Energia. Empresa de Pesquisa Energética. (2017a). Nota Técnica DEA 015/17: análise socioambiental das fontes energéticas do PDE 2026 (pp. 66). Rio de Janeiro: EPE.

Brasil. (2017b). Ministério de Minas e Energia. Empresa de Pesquisa Energética. Plano Decenal de Expansão de Energia 2026. Rio de Janeiro: EPE. Recuperado em 3 de outubro de 2019, de http://www.epe.gov.br/pt/publicacoes-dados-abertos/publicacoes/plano-decenal-de-expansao-deenergia-pde

Brasil. Ministério de Minas e Energia. Empresa de Pesquisa Energética. (2018a). Nota Técnica EPE 026/2018: análise socioambiental das fontes energéticas do PDE 2027. Rio de Janeiro: EPE. Recuperado em 3 de outubro de 2019, de http://www.epe.gov.br.

Brasil. Ministério de Minas e Energia. Empresa de Pesquisa Energética. (2018b). Nota Técnica EPE 027/2018 Metodologia para Avaliação Processual de Usinas Hidrelétricas (pp. 26). Rio de Janeiro: EPE. Recuperado em 3 de outubro de 2019, de https://www.epe.gov.br/sites-pt/publicacoes-dadosabertos/publicacoes/PublicacoesArquivos/publicacao-332/topico433/NT\%20An\%C3\%A1lise\%20Processual\%20de\%20UHEs\%20EPE\%20027-2018.pdf

Brasil. Ministério de Minas e Energia. Empresa de Pesquisa Energética. (2018c). Plano Decenal de Expansão de Energia 2027. Rio de Janeiro: EPE. Recuperado em 3 de outubro de 2019, de http://www.epe.gov.br/pt/publicacoes-dados-abertos/publicacoes/plano-decenal-de-expansao-deenergia-pde

Brasil. Ministério de Minas e Energia. Empresa de Pesquisa Energética. (2019a). Nota Técnica EPE-DEA-SMA 012/19 Análise socioambiental das fontes energéticas do PDE 2029. Rio de Janeiro: EPE.

Brasil. Ministério de Minas e Energia. Empresa de Pesquisa Energética. (2019b). Plano Decenal de Expansão de Energia 2029. Rio de Janeiro: EPE. Recuperado em 3 de outubro de 2019, de http://www.epe.gov.br/pt/publicacoes-dados-abertos/publicacoes/plano-decenal-de-expansao-deenergia-pde

Castro, T., Romeiro, P., \& Kelman, R., \& Hallot, C. (2013). Avaliação ambiental integrada em inventários hidrelétricos.

Duarte, C. G., Dibo, A. P. A., Siqueira-Gay, J., \& Sánchez, L. E. (2017). Practitioners' perceptions of the Brazilian environmental impact assessment system: results from a survey. Impact Assessment and Project Appraisal, 35(4), 293-309.

Fearnside, P. M. (2014). Impacts of Brazil's Madeira River Dams: unlearned lessons for hydroelectric development in Amazonia. Environmental Science \& Policy, 38, 164-172. http://dx.doi.org/10.1016/j.envsci.2013.11.004.

Fearnside, P. M. (2015a). Amazon dams and waterways: Brazil's Tapajós Basin plans. Ambio, 44(5), 429-439. http://dx.doi.org/10.1007/s13280-015-0642-z.

Fearnside, P. M. (2015b). Hidrelétricas Na Amazônia: impactos ambientais e sociais na tomada de decisões sobre grandes obras (Vol. 1). Manaus: Editora INPA. Recuperado em 3 de outubro de 2019, de http://acta.inpa.gov.br

Fearnside, P. M. (2016). Brazilian politics threaten environmental policies the country's environmental licensing system is threatened. Science, 353(6301), 746-748. http://dx.doi.org/10.1126/science.aag0254

Fearnside, P. M. (2017). Belo Monte: actors and arguments in the struggle over Brazil's most controversial Amazonian dam. Die Erde, 148(1), 14-26. http://dx.doi.org/10.12854/erde-148-27.

Hofmann, R. M. (2015). Gargalos do Licenciamento Ambiental Federal no Brasil. Brasília: Câmara dos Deputados.

Ritter, C. D., McCrate, G., Nilsson, R. H., Fearnside, P. M., Palme, U., \& Antonelli, A. (2017). Environmental impact assessment in Brazilian Amazonia: challenges and prospects to assess biodiversity. Biological Conservation, 206, 161-168.

Sánchez, L. E. (2010). The World Bank and the debate on hydropower licensing in Brazil. Impact Assessment and Project Appraisal, 28(4), 323-327. http://dx.doi.org/10.3152/146155110X12868988657017. 
Santos, S. M., \& Souza, M. P. (2011). Análise das contribuições potenciais da avaliação ambiental estratégica ao plano energético Brasileiro. Engenharia Sanitaria e Ambiental, 16(4), 369-378. http://dx.doi.org/10.1590/S1413-41522011000400008.

Tolmasquim, M. T. (2012). Perspectivas e planejamento do setor energético no Brasil. Estudos Avançados, $26(74), 247-260$.

World Bank. (2008). Licenciamento Ambiental de Empreendimentos Hidrelétricos no Brasil: Uma Contribuição para o Debate (Vol. 2: Relatório principal). Brasília: Banco Mundial. Escritório do Banco Mundial no Brasil.

Contribuições dos autores:

Felipe Affonso Dantas dos Santos: responsável pelo projeto, participou de todo planejamento, execução e confecção do manuscrito. Desde a concepção do artigo, estruturação, escrita do documento, pesquisa, coleta de amostra e análise de dados, revisão de literatura, discussão e revisão do texto final.

Laura de Brito Pereira Viana: revisão de literatura, análise de dados dos PDEs, e revisão do texto final. Elaboração e revisão do manuscrito.

Cristina Aparecida Gomes Nassar: estruturação, orientação do estudo, escrita, discussão e revisão do texto final.

\section{SIGLAS}

AAI Avaliação Ambiental Integrada

ANA Agência Nacional das Águas

ANEEL Agência Nacional de Energia Elétrica

ANP Agência Nacional do Petróleo, Gás Natural e Biocombustíveis

APCB Área(s) Prioritária(s) para a Conservação da Biodiversidade

CNPE Conselho Nacional de Política Energética

DEA Estudos da Demanda de Energia

DRDH Declaração de Reserva de Disponibilidade Hídrica

EIA/RIMA Estudo de Impacto Ambiental/Relatório de Impacto Ambiental

EPE Empresa de Pesquisa Energética

F.C Palmares Fundação Cultural Palmares

FUNAI Fundação Nacional do Índio

GW Giga watts

IBAMA Instituto Brasileiro do Meio Ambiente e dos Recursos Naturais Renováveis

IBGE Instituto Brasileiro de Geografia e Estatística

ICMBio Instituto Chico Mendes de Conservação da Biodiversidade

INCRA Instituto Nacional de Colonização e Reforma Agrária

IPHAN Instituto do Patrimônio Histórico e Artístico Nacional

kW Quilowatts

LI Licença de Instalação

LP Licença Prévia

LO Licença de Operação

LT Linha de Transmissão

MME Ministério de Minas e Energia

MW Megawatts

NT Nota Técnica

PDE Plano Decenal de Expansão de Energia

PEA População Economicamente Ativa

PNE Plano Nacional de Energia

SISA Sistema de Informações Socioambientais

TI Terra Indígena

TR Termo de Referência

UC Unidade de Conservação

UHE Usina Hidroelétrica 